ARTICULO DE INVESTIGACION

\title{
Uso y manejo de leña combustible en viviendas de seis localidades de Yucatán, México
}

\author{
Use and management of firewood in dwellings \\ of six localities from Yucatán, México
}

\author{
Joaquín Quiroz-Carranza1 y Roger Orellana1
}

\begin{abstract}
RESUMEN
Se analizó el patrón de preferencias en el uso de leña combustible en 1153 viviendas de seis localidades de Yucatán, mediante la aplicación de cuestionarios estructurados a informantes clave y muestreos en los sitios de extracción. Las localidades de estudio presentan heterogeneidad en la composición florística y distancia a la ciudad capital de estado, factores que modifican las preferencias y hábitos de consumo. El promedio de consumo en las localidades de estudio oscilo entre 1,26 y $2,89 \mathrm{~kg} / \mathrm{dia} / \mathrm{habitante}$, el promedio general de los sitios estudiados fue de 2,06 kg/día/habitante. La leña se extrae de la vegetación aledaña, la milpa y el solar. La colecta se hace a una distancia promedio de $3,8 \mathrm{~km}$ respecto a la vivienda. Los medios básicos para su transporte son el triciclo, la carga directa en la espalda del usuario y mediante uso de vehículo automotor. La leña se colecta fundamentalmente como material seco desprendido o seco en pie, debido a su menor peso, facilidad de acarreo y rápida ignición. Los usos fundamentales son la cocción de alimentos y calentamiento de agua de baño. 41 son las especies más usadas como combustible, pero las principales son: Acacia gaumeri, Havardia albicans, Lysiloma latisiliquum, Gymnopodium floribundum, Bursera simaruba, Caesalpinia gaumeri, Conocarpus erectus y Piscidia piscipula, debido a su mayor abundancia, fácil encendido, duración en el fuego y/o baja emisión de humo.
\end{abstract}

PALABRAS CLAVE:

Bioenergía, consumo de leña, leña, Yucatán.

\begin{abstract}
The consumption patterns of domestic firewood was analyzed in 1153 homes of six localities of Yucatan, Mexico, through questionnaires structured applied key informants and field samplings in the extraction sites. In the studied area a high heterogeneity was found, depending on the floristic composition of the site, as well as the relative distance from the place to the metropolis; both factors modify the consumption habits. The average consumption of firewood in the six studied places is of 2,06 $\mathrm{kg} / \mathrm{day} /$ person, coming from the neighbor vegetation, as well as from the cultivation field and the particular orchards. The recollection is made at a mean distance of $3,8 \mathrm{~km}$ from the towns. The basic transportation is by tricycles, the direct load in the collector's back and by truck. The firewood is collected basically as fallen or standing dry material, due to its low relative weight, transporting easiness and rapid ignition. The extracted firewood is used basically for the domestic consumption in the cooking of foods and water boiling. The interviewed users have preference for 41 woody species as fuel, but the main ones are: Acacia gaumeri, Havardia albicans, Lysiloma latisiliquum, Gymnopodium floribundum, Bursera simaruba, Caesalpinia gaumeri, Conocarpus erectus and Piscidia piscipula, due to their higher abundance, flammability, duration in the fire and low smoke emissions.
\end{abstract}

KEYWORDS:

Bioenergy, firewood consumption, firewood, Yucatán. 


\section{INTRODUCCIÓN}

La leña en México tiene múltiples usos entre los que destacan la calefacción de la vivienda, cocción de alimentos y calentamiento agua para consumo humano (Ghilardi et al., 2007). Así mismo se usa en pequeñas industrias tales como ladrilleras, talleres de alfarería, panaderías y otras (Masera y Fuentes, 2006). Esta diversidad de usos depende de las propiedades y características de la madera originaria de la que se extraiga la leña.

En México el uso de la leña como combustible, tiene varias consecuencias socioeconómicas y ambientales, entre las que destacan: 1) la satisfacción de los requerimientos de energía doméstica de una amplia población rural y urbana marginada que se estima entre 25 y 28 millones (Masera y Fuentes, 2006), de los cuales 19 millones la usan de forma exclusiva y 9 millones en combinación con gas LP (Díaz, 2000; Best, et al., 2006); 2) la perturbación de las comunidades vegetales, con repercusiones en la flora y fauna asociada, cuando se supera la capacidad de recuperación o resiliencia del ecosistema, 3) el impacto social, económico y de salud derivados de los procesos de acopio, transporte y combustión ineficiente, así como 4) los efectos potenciales sobre la atmósfera global, el clima y la salud humana; aunque, en este sentido se estima que las emisiones de $\mathrm{CO}_{2}$ derivadas de la combustión de leña no supera el $4 \%$ de la emisiones globales (Ghilardi et al., 2007). Así mismo se considera que la combustión de leña no produce $\mathrm{CO}_{2}$ neto, ya que este proceso libera la misma cantidad de $\mathrm{CO}_{2}$ que absorbe el ambiente (Masera y Fuentes, 2006).

Los patrones de consumo de leña en las comunidades humanas se modifican de acuerdo al clima local, los hábitos culi- narios, la forma de vida, la eficiencia del equipo utilizado en la cocina (fogón o estufa eficiente), la naturaleza de la leña y su disponibilidad; por factores como la tradición, el sabor dado a los alimentos, el tipo y origen del recipiente usado, los hábitos de cocina, el tipo de alimentos; el nivel de ingresos, el costo de la leña, la disponibilidad del recurso forestal y el número de especies utilizadas como leña. La cantidad de leña utilizada por la familia está en función del número de comidas durante el día y miembros de la familia, así como de tiempo que dura encendido el fogón (Reiche, 1985; del Amo, 2002; del Amo e Yllescas, 2002; Vergara, 2002 y Arias, 2002).

El uso y manejo doméstico de leña en las zonas rurales es un proceso fundamentalmente de autoconsumo, del cual se encargan generalmente las mujeres y los niños (Best, et al., 2006), que suelen hacerlo en las proximidades de la vivienda; mientras que el hombre lo hace de manera conjunta con sus labores agrícolas o en jornadas específicas. En ese caso, la leña se recoge de la vegetación dispersa en el ambiente local: árboles aislados, arbustos, restos de la poda de frutales, etc. (De Montalembert y Clément, 1983).

El uso y manejo de la leña es un proceso selectivo cuyo impacto sobre la cobertura vegetal depende de la intensidad de colecta y abundancia del recurso, de tal manera que:

a) Cuando se colectan las ramas caídas de los árboles, no se altera la estructura y función esenciales del bosque, por lo que la producción de combustible es relativamente estable y constante.

b) Si esta incluye el corte de ramas verdes de los árboles, se afecta la estructura y funcionamiento de la vegetación, 
se abren claros y se modifica el microclima de la selva. Ante esta perturbación la regeneración natural puede recuperar las condiciones previas a la colecta, siempre y cuando disminuya la presión extractiva.

c) Si se utiliza el árbol completo, se altera la estructura y función del parche, se abren condiciones a las herbáceas y arbustivas inútiles como fuente de leña. El agotamiento de las especies preferidas como leña, es la pauta para utilizar otras especies, lo que conlleva a un escalamiento destructivo de la selva o bosque (Parra, 1989).

El uso de la leña como recurso natural incluye los procedimientos para hacerse servir de algo, como son la extracción, la recolección y su aplicación. El manejo de la leña es un proceso que incorpora la apropiación, el conocimiento espacio-temporal del recurso, además de su transporte a los sitios de residencia. Este proceso puede diferenciarse por el grado o nivel de adjudicación, de tal manera que: i) la apropiación del recurso silvestre, se da cuando se localiza o bien se conoce la disponibilidad del recurso espacial y temporalmente; ii) la tolerancia que no incluye la dispersión, ni siembra, pero se tolera cuando otros miembros de la vegetación son eliminados. Se favorece su presencia al eliminar la competencia; iii) el fomento, incluye su dispersión, siembra y favorecer la reproducción de individuos evitando su depredación, la competencia y mejoramiento de algunas condiciones del medio en que se desarrolla y iv) el cultivo, cuando los individuos son seleccionados, protegidos de la competencia, la depredación y mejorando las condiciones del medio en que se desarrolla (Flores, 2001).

El uso y manejo de combustibles derivados de la biomasa tales como la leña, está regido por tres aspectos funda- mentales: el ambiental, el social y el económico.

En el aspecto ambiental, se provoca diversos efectos sobre las comunidades vegetales, sobre todo cuando con la extracción y colecta de leña se dan procesos sinérgicos de degradación (Orellana, 1992), como son la construcción de carreteras, casas unifamiliares o para el turismo, basureros comunales a cielo abierto, la explotación de poblaciones naturales, entre otras (Orellana y Durán, 1992; Flores y Espejel, 1994; Sánchez y Rebollar, 1999).

En el nivel social y económico, la leña y otros derivados de biomasa vegetal, representan la única fuente de combustible o una alternativa disponible para un segmento importante de la población. Adicionalmente genera procesos comerciales de pequeña escala e ingresos alternos para algunos pobladores, además las actividades culinarias están afectadas por patrones culturales, en donde la leña entrega sabores y olores especiales a los alimentos (Martínez, 1985).

El manejo y transporte de la leña combustible se realiza en unidades estandarizadas como son: la tarea, formada aproximadamente por 400 leños; la carga, constituida por 80 leños y el rollo por ocho o 12 leños en trozos de aproximadamente $45 \mathrm{~cm}$ de longitud y $6-8 \mathrm{~cm}$ de diámetro (Martínez, 1985).

De acuerdo con Ghildardi et al. (2007), en México el $25 \%$ de la población usa leña combustible como energético principal o en combinación con gas LP. En Yucatán, la aplicación de leña o carbón para uso doméstico se realizaba en 1990 , en el $37,1 \%$ de las viviendas, con una población equivalente al 41,1\% del total del estado (INEGI, 1990). Diez años después se usaba en el $39 \%$ de la 
viviendas, esto es 145465 viviendas (INEGI, 2000a). El promedio de habitantes por vivienda en el estado era en el año 2000 de 4,4 personas; esto representa que cerca de 640 mil habitantes en el estado satisfacían sus requerimientos energéticos en su vivienda a través de un combustible diferente al gas. Yucatán es uno de los doce estados de México con mayor consumo de leña como combustible en el ámbito doméstico (INEGI, 2000a).

La leña constituye un recurso fundamental de material combustible en muchas viviendas y los estudios sobre su uso y manejo en Yucatán son escasos. Únicamente se cuenta con la obra de Sánchez (1993), las referencias hacia el uso de las leguminosas como leña en Flores (2001) y los datos del INEGI (1990, 2000 y $2000 a$ ) sobre el tipo de combustible usado en las viviendas a nivel municipal. Debido a la necesidad de contar con información más detallada, se seleccionaron seis localidades que reflejan un gradiente de variación de comunidades vegetales, clima y distancia a la metrópoli, factores que modifican los hábitos de consumo.

\section{OBJETIVOS}

El propósito de este trabajo ha sido: a) estimar, desde la perspectiva del usuario, la cantidad de leña combustible consumida per cápita en las viviendas de la zona noroeste del estado de Yucatán, México; b) identificar las preferencias sobre las especies vegetales usadas como combustible; c) conocer las características socioeconómicas y culturales de los usuarios de leña, y d) determinar la abundancia local de las especies arbóreas y arbustivas preferidas como leña combustible en la región.

\section{METODOLOGÍA}

Para conocer las características socioeconómicas, culturales y los procedimientos que utiliza la población local para aprovechar la leña, así como las especies preferidas y los volúmenes de leña utilizados, se aplicó un cuestionario estructurado a informantes clave, entendiendo por estos a cualquier persona que pudiera brindar información detallada (Pelto y Pelto, 1978) sobre el uso y consumo de leña en la unidad de estudio: la vivienda. Este procedimiento se aplicó en 1153, que representan el $37,9 \%$ de las viviendas de seis localidades semirrurales de la región litoral oeste y metropolitana de Yucatán, donde se usa leña combustible de forma recurrente: Caucel (comisaría de Mérida), cabecera municipal de Ucú, Texán de Palomeque en el municipio de Hunucmá, cabecera municipal de Tetíz, cabecera municipal de Kinchil y cabecera municipal de Celestún (ver Figura 1).

La aplicación del cuestionario estructurado se llevó a cabo de la siguiente manera: utilizando los croquis de localidades publicado por INEGI (2000) a través de Sistema para la consulta de la Información Censal (SINCE, 2000), se realizaron en cada localidad, recorridos por manzana, iniciándolo en la esquina noroeste. Se seleccionaba únicamente aquellas casas donde se encontraba algún informante. En cada una de las viviendas se preguntaba al informante clave, hombre o mujer mayor de 18 años, habitante de la misma, sí en su vivienda se utilizaba leña como combustible o no. Si la respuesta era positiva, se aplicaba en cuestionario.

Si la persona lo autorizaba, se estimaba la cantidad de leña para consumo. Para cuantificar el peso promedio de los leños, se utilizó el promedio registrado de 95 leños secados al aire, mediante la medición de su longitud $(\mathrm{cm})$, grosor $(\mathrm{cm})$ y peso $(\mathrm{kg})$. 


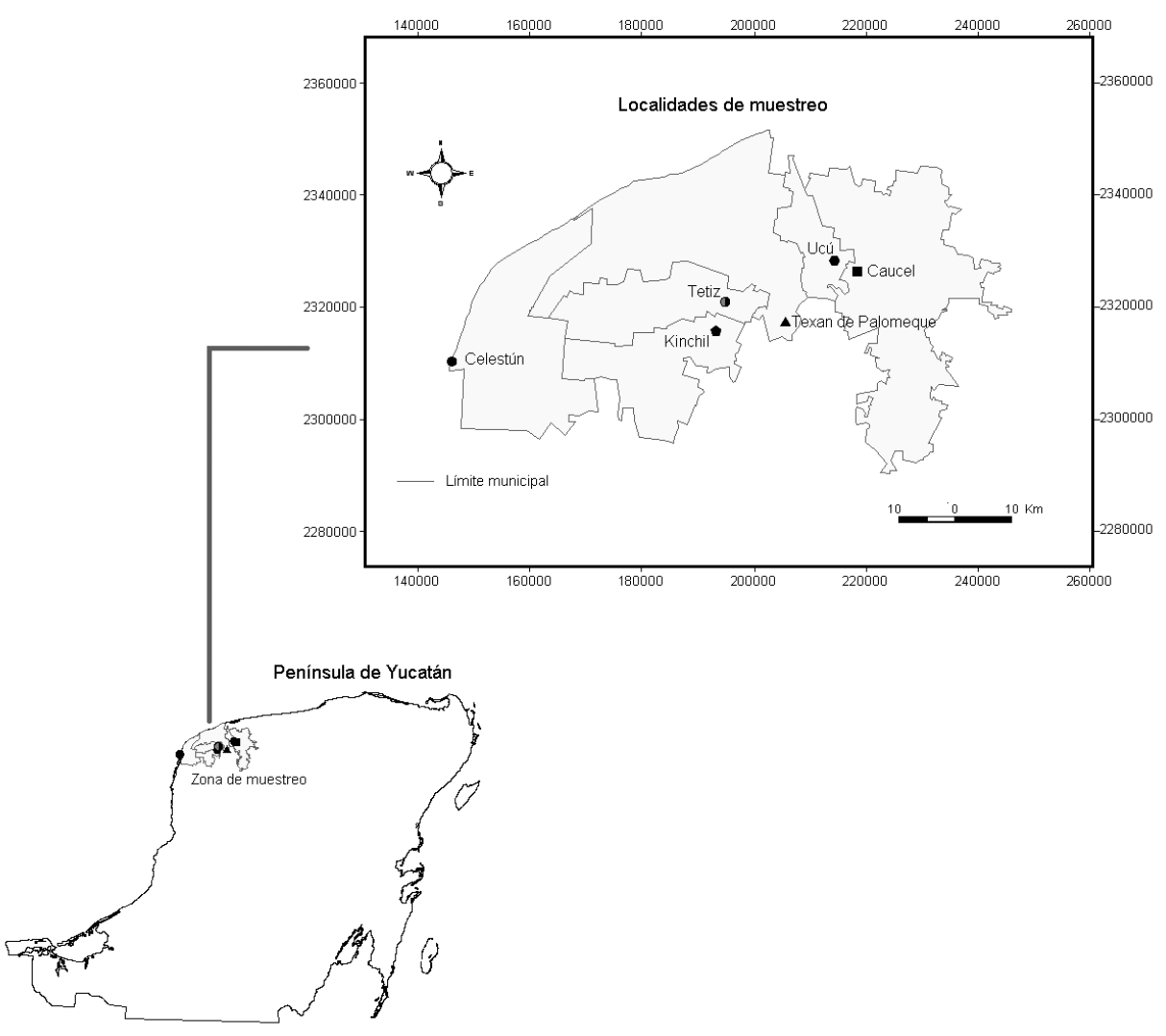

Figura 1. Mapa de localización de sitios de estudio.

Para conocer la abundancia de las especies utilizadas como leña se llevaron a cabo recorridos a las zonas de recolección señaladas por los habitantes; estos se hicieron en compañía de informantes clave de cada localidad, generalmente leñadores o recolectores. En cada una de las seis zonas se trazaron transectos de $200 \times 2 \mathrm{~m}(400$ $\mathrm{m}^{2}$ ). En el transecto correspondiente se cuantificaron e identificaron las especies arbóreas y arbustivas mayores de 2 $\mathrm{m}$ de altura y con un diámetro a la altura del pecho (DAP) mayor de $3 \mathrm{~cm}$. Esto se hizo con la finalidad de corroborar la presencia o ausencia en la vegetación aledaña a la localidad, las especies mencionadas por los usuarios. Los trozos de leña de las especies colectadas se transformaron en tablillas, se determinó su nombre científico, se registraron y entregaron al herbario del Centro de Investigación Científica de Yucatán (con siglas $\mathrm{CICY}$ ).

\section{Descripción de la zona de estudio}

El estado de Yucatán colinda al este con Quintana Roo y al oeste con Campeche. Los sitios de estudio se localizan en el extremo norte de la Península del mismo nombre, frente al Golfo de México y el canal de Yucatán. 
1. La comisaría de Caucel, pertenece al municipio de Mérida, y está ubicado en la región metropolitana del estado de Yucatán. Colinda al este con Mérida, al oeste con el municipio de Ucú, al norte con las comisarías de Cheuman y Dzityá y al sur con la comisaría de Susulá., todas pertenecientes al municipio de Mérida. Se encuentra a los $21^{\circ}$ $00^{\prime} 53^{\prime \prime}$ de latitud norte y a los $89^{\circ} 42^{\prime}$ $25^{\prime \prime}$ de longitud oeste (Ley Orgánica de los Municipios del Estado de Yucatán, 1988).

2. El municipio de Ucú se encuentra ubicado en la región metropolitana de la entidad, entre los $20^{\circ} 58^{\prime}$ y $21^{\circ} 10^{\prime}$ de latitud norte y entre los $89^{\circ} 44^{\prime}$ y $89^{\circ} 51^{\prime}$ de longitud oeste. Colinda al norte con el municipio de Progreso; al sur con el municipio de Umán; al este con el municipio de Mérida y al oeste con el municipio de Hunucmá, se encuentra a $15 \mathrm{~km}$ de la Ciudad de Mérida (Ley Orgánica de los Municipios del Estado de Yucatán, 1988).

3. La comisaría de Texan de Palomeque pertenece al Municipio de Hunucmá, el cual se encuentra ubicado en la región del litoral oeste del estado de Yucatán, entre los meridianos $89^{\circ} 48^{\prime}$ y $90^{\circ} 12^{\prime}$ de longitud oeste y los paralelos $20^{\circ} 55^{\prime}$ y $20^{\circ} 14^{\prime}$ de latitud norte. Sus límites territoriales son: al norte con el Golfo de México; al sur con los municipios de Tetíz y Samahil, al este con Progreso, Ucú y Umán y al oeste con Celestún. La cabecera municipal se encuentra a 25 $\mathrm{Km}$. de la Ciudad de Mérida, en dirección oeste (Ley Orgánica de los Municipios del Estado de Yucatán, 1988).

4. El municipio de Tetíz se encuentra ubicado en la región litoral oeste de la entidad, entre los $20^{\circ} 56^{\prime}$ y $21^{\circ} 00^{\prime}$ de latitud Norte y entre los $89^{\circ} 54^{\prime}$ y $90^{\circ} 11^{\prime}$ de longitud oeste. Sus límites territoriales son: al norte y este con el municipio de Hunucmá; al sur con el municipio de
Kinchil; y al oeste con el municipio de Celestún. La cabecera municipal se encuentra a 38 km de Mérida (Ley Orgánica de los Municipios del Estado de Yucatán, 1988).

5. El municipio de Kinchil se encuentra ubicado en la región del litoral oeste del estado de Yucatán, entre los meridianos $89^{\circ} 54^{\prime}$ y $90^{\circ} 12^{\prime}$ de longitud oeste y los paralelos $20^{\circ} 45^{\prime}$ y $20^{\circ} 55^{\prime}$ de latitud norte. Sus límites territoriales son: al norte con el municipio de Tetíz; al sur con Kopomá, al este con Samanhil y Umán y al oeste con Celestún (Ley Orgánica de los Municipios del Estado de Yucatán, 1988).

6. El municipio de Celestún se encuentra ubicado en la región litoral oeste de la entidad, entre los $20^{\circ} 46^{\prime}$ y $21^{\circ} 06^{\prime}$ de latitud Norte y entre los $90^{\circ}$ $11^{\prime}$ y $90^{\circ} 25^{\prime}$ de longitud oeste, tiene una altura promedio de 3 metros sobre el nivel del mar. Sus límites territoriales son: al norte con el Golfo de México; al sur con el municipio de Maxcanú; al este los municipios de Kinchil, Tetíz y Hunucmá y al oeste con el Golfo de México y el estado de Campeche. Se encuentra a 78 km de Mérida (Ley Orgánica de los Municipios del Estado de Yucatán, 1988).

De acuerdo con INEGI (2000) las localidades de estudio Caucel, Ucú, Texán de Palomeque, Tetíz, Kinchil y Celestún, reunían en el año 2000 un total 5580 viviendas con una población de 27484 habitantes; En el 59,2 \% de las viviendas se reportaba uso de leña como combustible fundamental habiendo sido estimado 4,8 , el promedio de habitantes por vivienda. Esto significa que, en ese año, en las seis localidades 16686 habitantes usaban como energético cotidiano de su vivienda la leña $u$ otros combustibles no derivadas de hidrocarburos. 


\section{Características ambientales de la zona de estudio}

La superficie ocupada por los municipios de estudio, están localizados en una zona llana, con una altitud promedio sobre el nivel del mar de 2 a 8 metros. Debido a que toda la zona es cárstica, no hay cuerpos de agua superficiales, como producto de la excesiva permeabilidad de los terrenos. Sin embargo existe un complejo sistema hidrológico subterráneo y es común la presencia de cenotes, aguadas y hondonadas. Los suelos son someros y pedregosos, con abundantes afloramientos rocosos representados por la asociación de litosoles y rendzinas, conocidos en maya como Tsekel y K'an kab. La temperatura media anual es mayor de $26{ }^{\circ} \mathrm{C}$ y la precipitación pluvial va de los $500 \mathrm{~mm}$ en el extremo noroeste a los $1000 \mathrm{~mm}$ en la porción sureste. Por lo general la época de lluvias se inicia en mayo y termina en octubre. En los municipios de estudio y parte de los municipios aledaños se ubican en los subtipos climáticos, de acuerdo con la clasificación climática de Köppen modificado por García (2004) en la transición del $A w_{0}\left(i^{\prime}\right)$ cálido, el mas seco de los subhúmedos, con régimen de lluvias en verano, y hacia el este con alto porcentaje de lluvia invernal y el $B S_{1}\left(h^{\prime}\right) w^{\prime \prime}(i)$ o semiárido y cálido con régimen de lluvias en verano que presenta un porcentaje muy bajo de lluvias de invierno, con poca oscilación térmica, y con un periodo de sequía pluviométrica de entre 7 y 9 meses. (Duch, 1991; Orellana et al, 2003).

Los tipos de vegetación en Celestún y Hunucmá son de matorral de dunas costeras, manglar y petenes (islas de vegetación de selva mediana inmersa en el manglar), selva baja decidua con cactáceas candelabriformes y selva baja caducifolia. En Kinchil, Tetíz, Ucú y Caucel se presenta la selva baja con cactáceas candelabriformes y selva baja caducifolia (Flores y Espejel, 1994; Olmsted et al, 1999). Las comunidades vegetales que componen esta vegetación, prestan servicios ambientales diversos y son sitios de reproducción de múltiples especies de la fauna silvestre (Howell \& Webb, 1995; Campbell, 1998; Lee, 2000).

\section{RESULTADOS}

El número de viviendas a cuyos habitantes se aplicó el cuestionario estructurado fue de 1153, que según el Censo de Población y Vivienda (INEGI, 2000) representa el $37,9 \%$ de los hogares de la zona donde se consume leña de forma cotidiana. En las viviendas visitadas, habitan 5443 personas en un promedio por vivienda de 4,7 . El $50,8 \%$ de los habitantes son mujeres y el $49,2 \%$ hombres (tabla 1).

Las actividades principales de los habitantes de las viviendas, manifestadas por los informantes clave fueron la siguientes: estudiante (31\%), actividades del hogar $(20 \%)$, empleado $(11,9 \%)$, pescador $(8,2 \%)$, obrero $(7,0 \%)$, campesino $(5,7 \%)$, oficios diversos como plomero y electricista $(4,6 \%)$, albañil $(4,1 \%)$, comerciante $(2,6 \%)$, jubilado $(1,3 \%)$, trabajo doméstico asalariado $(1,3 \%)$, leñador $(0,9 \%)$, profesionista $(0,5 \%)$ y apicultor $(0,2 \%)$ (Tabla 2$)$.

La leña se adquiere en el 39,3\% de los casos con los leñadores, 53,3\% directamente en la vegetación aledaña, 4,2\% se extrae de la milpa y $3,0 \%$ del solar. La distancia promedio de la vivienda al área de colecta es de $3,8 \mathrm{~km}$; el transporte utilizado para el traslado de la leña en el $70,5 \%$ de los casos es el triciclo de carga, $12 \%$ la carga directa es directa sobre la espalda, 9,8\% por medio de camioneta de carga, $5 \%$ en bicicleta y $2,6 \%$ por medio de carreta tirada por mulas. 


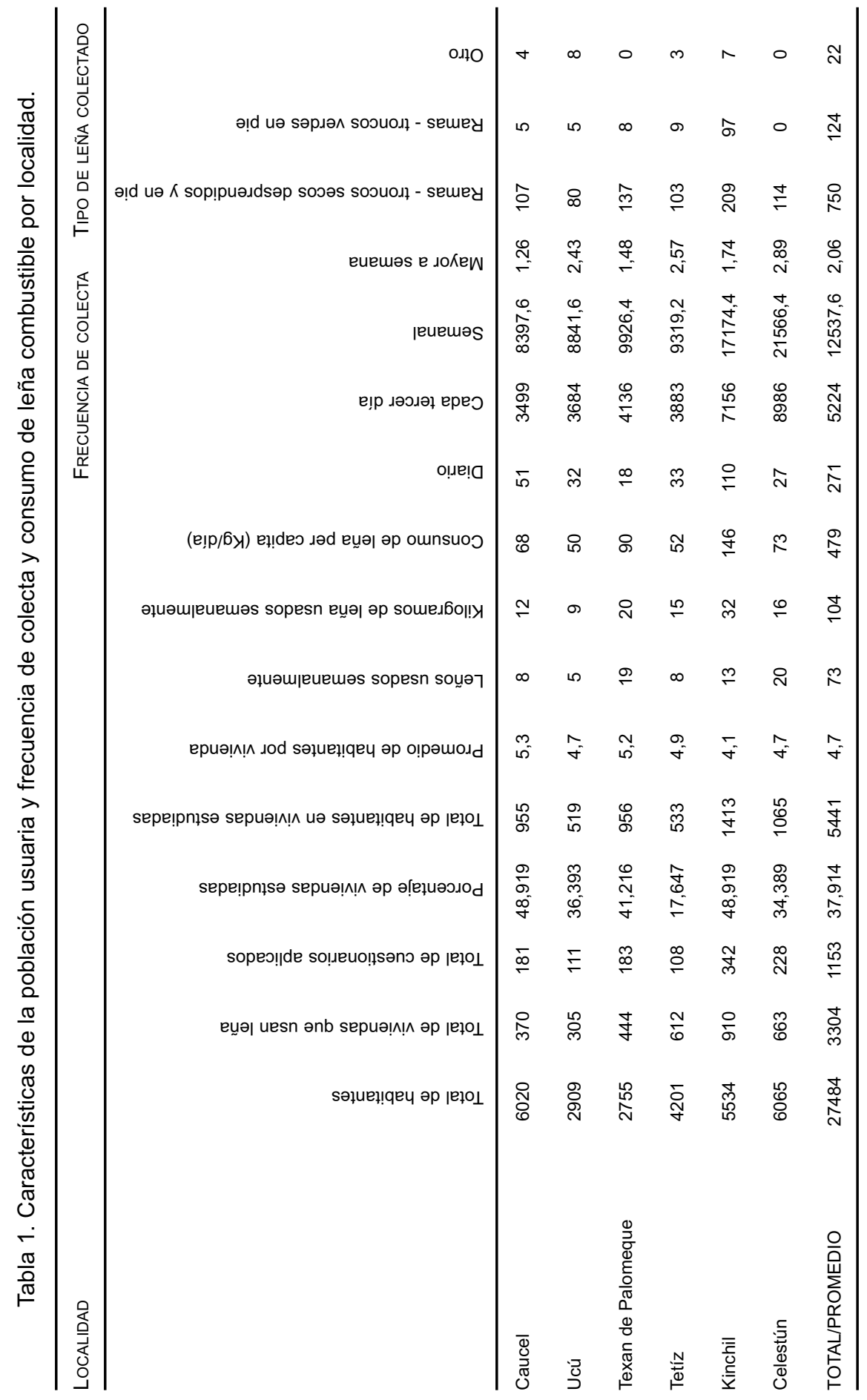


Tabla 2. Actividades principales de los habitantes de la zona de estudio.

\begin{tabular}{|c|c|c|c|c|c|c|c|c|c|c|c|c|c|c|c|}
\hline Localidad & 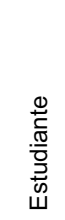 & $\begin{array}{l}\overline{\bar{\pi}} \\
\text { О } \\
\text { 우 }\end{array}$ & $\begin{array}{l}\frac{}{0} \\
\frac{\mathbb{D}}{0} \\
\frac{0}{0} \\
\text { யे }\end{array}$ & 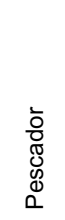 & $\begin{array}{l}\frac{0}{0} \\
\frac{0}{0}\end{array}$ & 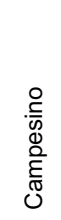 & $\begin{array}{l}\text { 0 } \\
.0 \\
\frac{0}{10} \\
00 \\
.0 \\
.0 \\
0\end{array}$ & 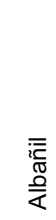 & $\begin{array}{l}\frac{O}{0} \\
\frac{0}{\Phi} \\
\frac{\delta}{0} \\
0\end{array}$ & $\frac{\frac{0}{0}}{\frac{\pi}{\overline{0}}}$ & 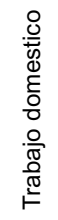 & 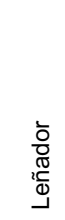 & $\begin{array}{l}\frac{\pi}{0} \\
\frac{0}{2} \\
\frac{0}{0} \\
\frac{0}{0} \\
\frac{0}{0}\end{array}$ & $\frac{\overline{0}}{\frac{0}{3}} \frac{0}{\frac{0}{2}}$ & $\begin{array}{l}\bar{\pi} \\
\frac{\pi}{0}\end{array}$ \\
\hline Caucel & 140 & 0 & 75 & 0 & 36 & 9 & 40 & 19 & 14 & 30 & 0 & 0 & 0 & 0 & 363 \\
\hline Ucú & 168 & 106 & 38 & 1 & 49 & 28 & 20 & 14 & 15 & 3 & 10 & 10 & 9 & 0 & 471 \\
\hline Texan de Palomeque & 120 & 0 & 16 & 0 & 39 & 27 & 13 & 47 & 6 & 8 & 2 & 4 & 0 & 0 & 282 \\
\hline Tetíz & 133 & 171 & 49 & 3 & 18 & 44 & 16 & 15 & 15 & 3 & 14 & 0 & 1 & 4 & 486 \\
\hline Kinchil & 349 & 353 & 162 & 23 & 81 & 71 & 44 & 30 & 27 & 29 & 16 & 16 & 5 & 1 & 1207 \\
\hline Celestún & 82 & 10 & 42 & 235 & 0 & 3 & 13 & 5 & 5 & 0 & 0 & 0 & 0 & 0 & 395 \\
\hline Total/promedio & 992 & 640 & 382 & 262 & 223 & 182 & 146 & 130 & 82 & 73 & 42 & 30 & 15 & 5 & 3204 \\
\hline Porcentaje & 31,0 & 20,0 & 11,9 & 8,2 & 7,0 & 5,7 & 4,6 & 4,1 & 2,6 & 2,3 & 1,3 & 0,9 & 0,5 & 0,2 & 100 \\
\hline
\end{tabular}

Las unidades de medida fueron $46,9 \%$ el rollo o tercio que aglutina de 12 a 15 leños, $48,8 \%$ el triciclo o carga con $60-80$ leños y $4,1 \%$ la tarea o camioneta con $250-300$ leños. Como se mencionó, en el $39,3 \%$ de los casos la leña se le compra a algún leñador y en el ámbito familiar, la colecta la realizan en el $81 \%$ de los casos el padre y la madre, $12,1 \%$ los hijos y $6,5 \%$ participan toda la familia. La colecta de leña, por lo general se realiza en el $51,6 \%$ de forma semanal, $29,2 \%$ quincenal y/o mensual, $11,2 \%$ cada tercer día y $7,9 \%$ diariamente. El consumo de leña promedio de las seis localidades de estudios fue de 2,06 $\mathrm{kg} / \mathrm{dia} /$ habitante, con una promedio local de 1,26 en Caucel, 2,43 en Ucú, 1,48 en Texán de Palomeque, 2,57 en Tetíz, 1,74 en Kinchil y 2,89 en Celestún, variaciones que pueden estar asociadas a disponibilidad de sitios de extracción, cercanía de una ciudad, entre otros factores.

En $42,4 \%$ de las viviendas usan leña como combustible alterno al gas, en el
$3,9 \%$ se usa carbón y en el $2,6 \%$ algún otro combustible como petróleo, cartón, aserrín, etc.). En el $65 \%$ de los casos el tipo de material colectado son ramas y troncos secos desprendidos y en pie, $14,2 \%$ ramas y troncos verdes en pie y $1,9 \%$ son de casos de derribos de todo el árbol. La percepción que manifestaron los informantes clave sobre la abundancia del recurso fue, en el $65 \%$ de los casos, que la leña ya no se consigue igual que antes y el $71 \%$ indicó que consideran importante hacer plantaciones como fuente para leña.

Del total de informantes, 936 mencionaron 41 especies vegetales utilizadas como leña en las seis localidades, mismas que se agrupan en 19 familias botánicas, tal y como se indica en la tabla 3: Fabaceae con 15 especies, Anacardiaceae con tres especies, Anonaceae, Combretaceae, Malvaceae, Polygonaceae, Rutaceae y Sapindaceae cada una con dos especies. Las once familias restantes, con una sola especie. 


\section{Tabla 3. Frecuencia de uso y frecuencia relativa de especies usadas como leña en los hogares de la zona de estudio.}

\begin{tabular}{|c|c|c|c|c|c|}
\hline Número & $\begin{array}{c}\text { Frecuencia } \\
\text { de uso }\end{array}$ & $\begin{array}{c}\text { Frecuencia } \\
\text { relativa } \\
\text { de uso }\end{array}$ & Nombre común & Nombre científico & Familia \\
\hline 1 & 251 & 26,82 & Box katsim & Acacia gaumeri S,F, Blake & Fabaceae \\
\hline 2 & 171 & 18,27 & Chukum & Havardia albicans (Kunth) Britton \& Rose & Fabaceae \\
\hline 3 & 158 & 16,88 & tsalam & Lysiloma latisiliquum (L,) Benth, & Fabaceae \\
\hline 4 & 88 & 9,40 & ts'i' ts'ilché & Gymnopodium floribundum Rolfe & Polygonaceae \\
\hline 5 & 51 & 5,45 & chacáh & Bursera simaruba L,(Sarg,) & Burseraceae \\
\hline 6 & 38 & 4,06 & kitinché & Caesalpinia gaumeri Greenm, & Fabaceae \\
\hline 7 & 30 & 3,21 & botoncillo & Conocarpus erectus $\mathrm{L}$, & Combretaceae \\
\hline 8 & 27 & 2,88 & habín & Piscidia piscipula (L,) Sarg, & Fabaceae \\
\hline 9 & 15 & 1,60 & sak Katsim & Mimosa bahamensis Benth, & Fabaceae \\
\hline 10 & 15 & 1,60 & mangle & Rhizophora mangle L, & Rhizophoraceae \\
\hline 11 & 12 & 1,28 & huaxim & Leucaena leucocephala (Lam,) de Wit, & Fabaceae \\
\hline 12 & 9 & 0,96 & ramón & Brosimum alicastrum Sw, & Moraceae \\
\hline 13 & 8 & 0,85 & naranja & Citrus sinensis (L,) Osbeck & Rutaceae \\
\hline 14 & 7 & 0,75 & tuché & Caesalpinia yucatanensis Greenm, & Fabaceae \\
\hline 15 & 7 & 0,75 & huaya local & Talisia olivaeformis (Kunth) Radlk, & Sapindaceae \\
\hline 16 & 5 & 0,53 & limón & Citrus aurantifolia (Christh,) Swingle & Rutaceae \\
\hline 17 & 5 & 0,53 & sakokom & Laguncularia racemosa (L,)C,F,Gaertn, & Combretaceae \\
\hline 18 & 3 & 0,32 & bokanche & Capparis incana Kunth & Capparidaceae \\
\hline 19 & 3 & 0,32 & Tinto & Haematoxylon campechianum $\mathrm{L}$, & Fabaceae \\
\hline 20 & 3 & 0,32 & kuchel & Machaonia lindeliana Baillon & Rubiaceae \\
\hline 21 & 3 & 0,32 & ciruela & Spondias purpurea L, & Anacardiaceae \\
\hline 22 & 3 & 0,32 & tamarindo & Tamarindus indica L, & Fabaceae \\
\hline 23 & 2 & 0,21 & chimay & Acacia pennatula (Cham \& Schltdl,) Benth, & Fabaceae \\
\hline 24 & 2 & 0,21 & cedro rojo & Cedrela odorata L, & Meliaceae \\
\hline 25 & 2 & 0,21 & yax ek & $\underline{\text { Chloroleucon mangense (Jacq.) Britt\& Rose }}$ & Fabaceae \\
\hline 26 & 2 & 0,21 & chechem & Metopium brownei (Jacq,) Urb, & Anacardiaceae \\
\hline 27 & 2 & 0,21 & k'anchunuup & Thouinia paucidentata Radlk, & Sapindaceae \\
\hline 28 & 1 & 0,11 & guanábana & Annona muricata L, & Annonaceae \\
\hline 29 & 1 & 0,11 & saramuyo & Annona squamosa $\mathrm{L}$, & Annonaceae \\
\hline 30 & 1 & 0,11 & chulul & Apoplanesia paniculada C, Presl, & Fabaceae \\
\hline 31 & 1 & 0,11 & achiote & Bixa Orellana (Kuntze)Standl \& L,O,Wills, & Bixaceae \\
\hline 32 & 1 & 0,11 & mandarina & Citrus reticulata Blanco & Rutaceae \\
\hline 33 & 1 & 0,11 & siricote & Cordia dodecandra A,D,C, & Boraginaceae \\
\hline 34 & 1 & 0,11 & sinanché & Diphysa carthagenensis Jacq, & Fabaceae \\
\hline 35 & 1 & 0,11 & pixoy & Guazuma ulmifolia Lam, & Malvaceae \\
\hline 36 & 1 & 0,11 & mango & Mangifera indica L, & Anacardiaceae \\
\hline 37 & 1 & 0,11 & sapote,ya" & Manilkara zapota (L,) P,Royen & Sapotaceae \\
\hline 38 & 1 & 0,11 & sak its'a & Neomillspaugia emarginata (Gross) Blake & Polygonaceae \\
\hline 39 & 1 & 0,11 & katkut & Parmentiera millspaughiana L,O,Williams & Bignoniaceae \\
\hline 40 & 1 & 0,11 & ts' iuché & Pithecellobium dulce (Roxb,) Benth, & Fabaceae \\
\hline 41 & 1 & 0,11 & algodoncillo & Thespesia populnea (L,) Sol, Ex Correa & Malvaceae \\
\hline
\end{tabular}




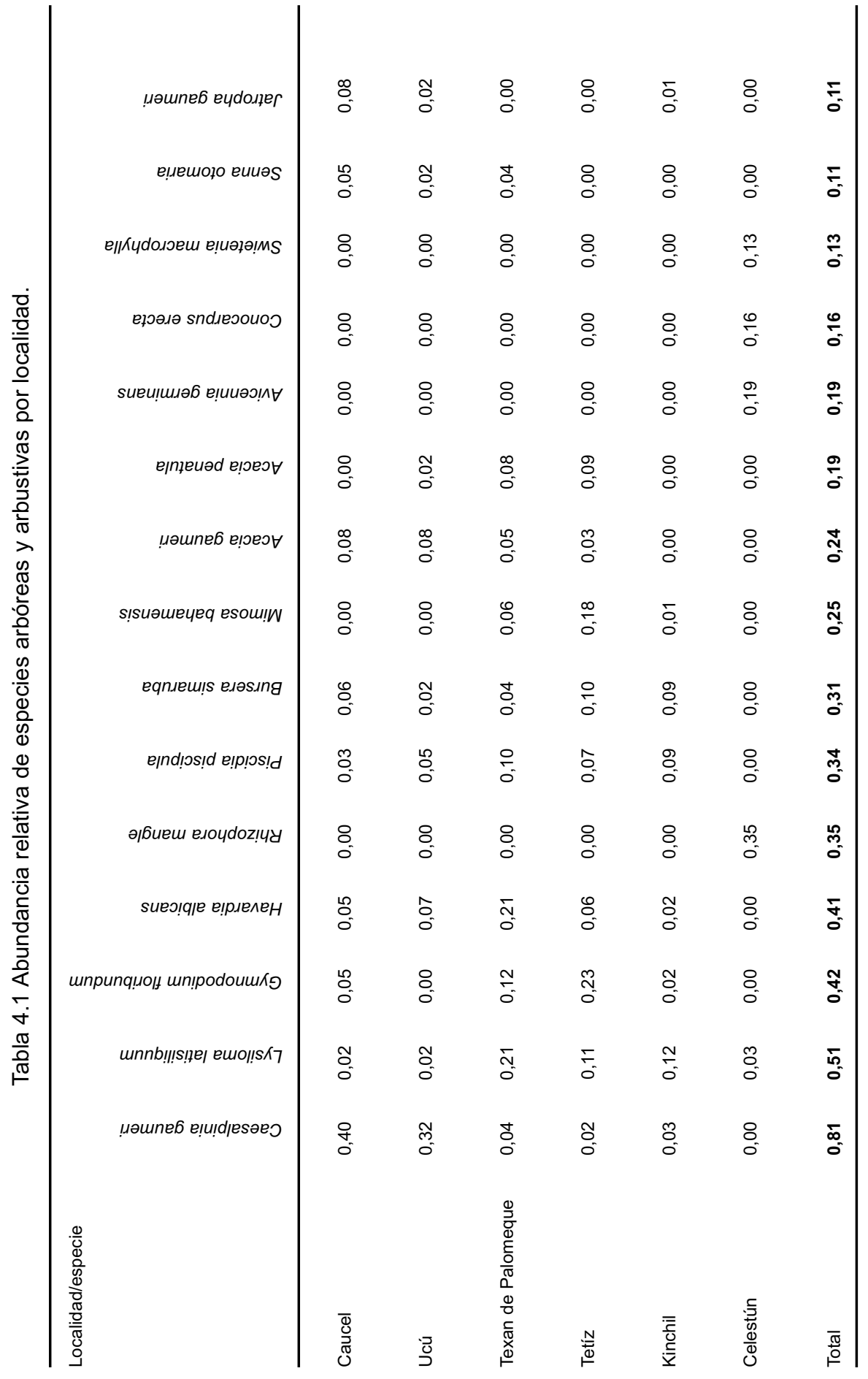




\begin{tabular}{|c|c|c|c|c|c|c|c|}
\hline ејечdәэоวпә/ еиәеэпә7 & $\begin{array}{l}8 \\
0\end{array}$ & $\begin{array}{l}\tilde{O} \\
\delta \\
0\end{array}$ & $\begin{array}{l}8 \\
0\end{array}$ & $\begin{array}{l}8 \\
0\end{array}$ & $\begin{array}{l}\delta \\
0 \\
0\end{array}$ & $\begin{array}{l}8 \\
0\end{array}$ & ஜ̊ \\
\hline !پәшпе6 хәң!^ & : & \& & $\begin{array}{l}8 \\
0 \\
0\end{array}$ & $\begin{array}{l}8 \\
0 \\
0\end{array}$ & $\begin{array}{l}\text { O } \\
0 \\
0\end{array}$ & $\begin{array}{l}8 \\
0 \\
0\end{array}$ & $\begin{array}{l}\text { J } \\
0\end{array}$ \\
\hline ełeəuno soגkdso!a & 8 & 8 & 8 & ס & $\begin{array}{l}\delta \\
0\end{array}$ & 8 & $\begin{array}{l}\text { J } \\
0\end{array}$ \\
\hline еріэп। sәчұиеишко & $\begin{array}{l}8 \\
0\end{array}$ & $\begin{array}{l}\tilde{O} \\
\delta \\
0\end{array}$ & $\begin{array}{l}8 \\
0\end{array}$ & $\begin{array}{l}8 \\
0\end{array}$ & $\begin{array}{l}\widetilde{O} \\
\delta \\
0\end{array}$ & $\begin{array}{l}8 \\
0\end{array}$ & $\begin{array}{l}\text { J } \\
0\end{array}$ \\
\hline sәріочdıоше еорелел/V & $\begin{array}{l}N \\
\text { O } \\
\text { O. }\end{array}$ & $\begin{array}{l}\tilde{O} \\
\text { O. }\end{array}$ & $\begin{array}{l}8 \\
0 \\
0\end{array}$ & O & $\begin{array}{l}8 \\
0 \\
0\end{array}$ & \& & $\begin{array}{l}\text { J } \\
0\end{array}$ \\
\hline eəundund se!puods & $\begin{array}{l}8 \\
0\end{array}$ & $\begin{array}{l}8 \\
0\end{array}$ & $\begin{array}{l}8 \\
0\end{array}$ & $\begin{array}{l}8 \\
0\end{array}$ & $\begin{array}{l}\text { J } \\
0\end{array}$ & $\begin{array}{l}8 \\
0\end{array}$ & $\begin{array}{l}\text { J } \\
0\end{array}$ \\
\hline 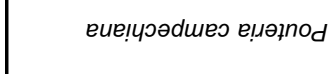 & \& & 8 & $\begin{array}{l}8 \\
0\end{array}$ & 8 & 8 & $\begin{array}{l}12 \\
0 \\
0\end{array}$ & ᄂ \\
\hline 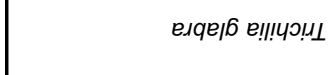 & ০ & $\begin{array}{l}n \\
0 \\
0\end{array}$ & $\begin{array}{l}8 \\
0\end{array}$ & $\begin{array}{l}8 \\
0 \\
0\end{array}$ & 8 & 8 & $\stackrel{2}{0}$ \\
\hline elodes exeyl!uew & \& & 8 & : & 8 & O & $\stackrel{2}{0}$ & $\stackrel{\ell}{0}$ \\
\hline еие!чगәдшео ио|Кхојешәен & : & 8 & : & 8 & $\begin{array}{l}0 \\
0 \\
0\end{array}$ & 8 & ᄂ \\
\hline щпиеग!хәщ ешәңรох $\exists$ & $\begin{array}{l}8 \\
0\end{array}$ & $\begin{array}{l}8 \\
0\end{array}$ & $\begin{array}{l}\mathscr{O} \\
0 \\
0\end{array}$ & $\begin{array}{l}8 \\
0 \\
0\end{array}$ & $\begin{array}{l}\text { ח̊ } \\
0\end{array}$ & $\begin{array}{l}8 \\
0\end{array}$ & $\begin{array}{l}8 \\
0\end{array}$ \\
\hline 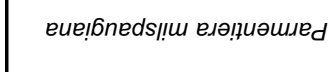 & $\begin{array}{l}\text { ס } \\
0\end{array}$ & $\begin{array}{l}\widetilde{\sigma} \\
\delta \\
0\end{array}$ & $\begin{array}{l}8 \\
0\end{array}$ & 8 & $\begin{array}{l}\overline{0} \\
0 \\
0\end{array}$ & 8 & 8 \\
\hline sиәэәлоqле әоК/еdıен & \& & $\begin{array}{l}8 \\
0\end{array}$ & $\begin{array}{l}8 \\
0 \\
0\end{array}$ & $\begin{array}{l}8 \\
0\end{array}$ & $\begin{array}{l}\hat{0} \\
0 \\
0\end{array}$ & 8 & $\hat{0}$ \\
\hline !әимолq шп!dојәW & : & 8 & : & 8 & $\begin{array}{l}\text { O } \\
0\end{array}$ & mo & $\hat{0}$ \\
\hline әsиәБиеш иоэпәоло/чว & $\begin{array}{l}\text { O̊ } \\
\text { O. }\end{array}$ & O̊ & : & \& & $\begin{array}{l}\text { N. } \\
\text { O. }\end{array}$ & : & $\begin{array}{l}\infty \\
0 \\
0\end{array}$ \\
\hline eиeou! s!̣eddeว & $\begin{array}{l}\infty \\
0 \\
0\end{array}$ & 8 & $\begin{array}{l}\tilde{\sigma} \\
0\end{array}$ & 8 & $\bar{\delta}$ & 8 & 응 \\
\hline 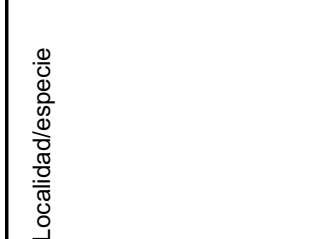 & $\begin{array}{l}\bar{\Phi} \\
\overline{\widetilde{J}} \\
0\end{array}$ & "כ & 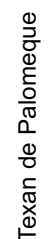 & $\stackrel{N}{\mathbb{N}}$ & $\begin{array}{l}\overline{\bar{E}} \\
\overline{0} \\
\frac{\bar{y}}{2}\end{array}$ & $\begin{array}{l}\frac{5}{0} \\
\frac{0}{\mathbb{D}} \\
0\end{array}$ & 要 \\
\hline
\end{tabular}




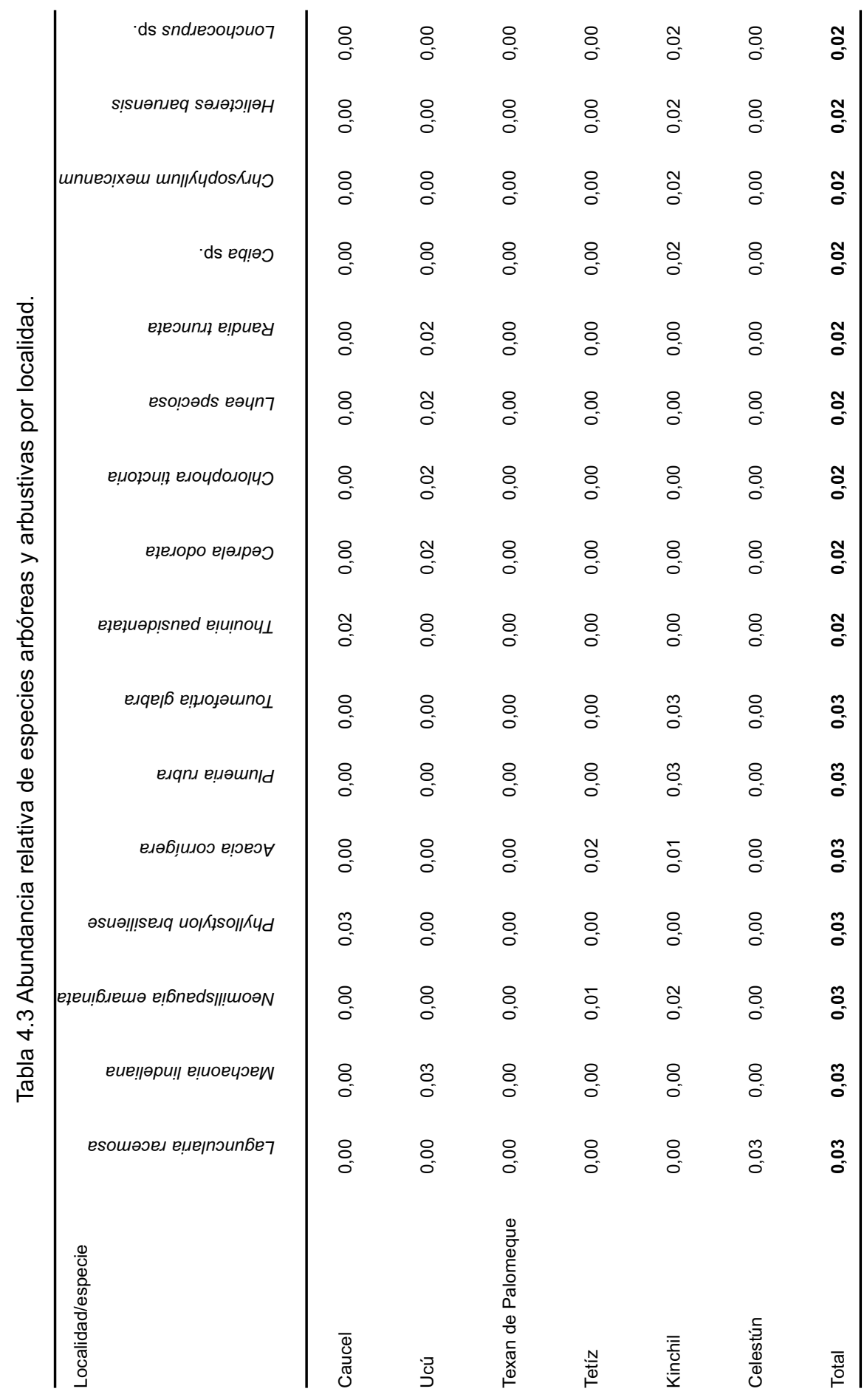




\begin{tabular}{|c|c|c|c|c|c|c|c|}
\hline е!|оц!әербКше еиеұиошешәqе & 8 & : & $\begin{array}{l}8 \\
0 \\
0\end{array}$ & 8 & $\begin{array}{l}\delta \\
0 \\
0\end{array}$ & $\begin{array}{l}8 \\
0 \\
0\end{array}$ & $\bar{o}_{0}$ \\
\hline 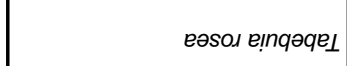 & 8 & 8 & 8 & 8 & $\delta_{0}$ & $\begin{array}{l}8 \\
0\end{array}$ & $\bar{\delta}_{0}$ \\
\hline 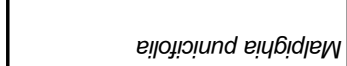 & 8 & ¿ & $\begin{array}{l}8 \\
0\end{array}$ & 8 & $\begin{array}{l}\delta \\
0 \\
0\end{array}$ & 8 & $\bar{o}_{0}$ \\
\hline ds emsuimiey & 8 & 응 & $\begin{array}{l}8 \\
0\end{array}$ & $\begin{array}{l}8 \\
0 \\
0\end{array}$ & $\delta_{0}$ & 응 & $\delta_{0}^{-}$ \\
\hline еұеqои еәдшен & 8 & 8 & $\begin{array}{l}8 \\
0\end{array}$ & 8 & $\begin{array}{l}\delta \\
0 \\
0\end{array}$ & $\begin{array}{l}8 \\
0\end{array}$ & $\delta_{0}^{\delta}$ \\
\hline 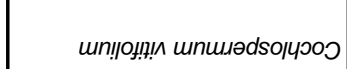 & 8 & 8 & 8 & $\begin{array}{l}8 \\
0\end{array}$ & $\delta_{0}$ & 8 & ${ }_{0}^{\delta}$ \\
\hline 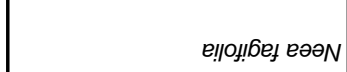 & $\begin{array}{l}8 \\
0\end{array}$ & $\begin{array}{l}8 \\
0 \\
0\end{array}$ & 8 & $\delta_{0}$ & $\begin{array}{l}8 \\
0\end{array}$ & $\begin{array}{l}8 \\
0\end{array}$ & $\delta_{0}$ \\
\hline әznos sn!nosop!uכ & 8 & 8 & 8 & $\delta_{0}$ & 8 & 8 & $\delta_{0}$ \\
\hline sı!suәңешәәеп6 ециquппоо & 8 & 8 & $\begin{array}{l}\bar{\delta} \\
0\end{array}$ & 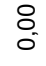 & : & : & $\delta_{0}^{-}$ \\
\hline әэІпр щп!qо॥әэәч!!d & $\begin{array}{l}8 \\
0\end{array}$ & 8 & $\begin{array}{l}8 \\
0\end{array}$ & 8 & $\begin{array}{l}\delta \\
0\end{array}$ & 8 & $\delta_{0}^{\delta}$ \\
\hline 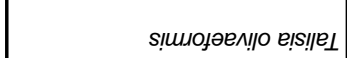 & $\begin{array}{l}8 \\
0\end{array}$ & $\begin{array}{l}8 \\
0\end{array}$ & $\begin{array}{l}8 \\
0\end{array}$ & $\begin{array}{l}8 \\
0 \\
0\end{array}$ & $\begin{array}{l}\bar{\delta} \\
0\end{array}$ & $\begin{array}{l}8 \\
0\end{array}$ & $\begin{array}{l}\overline{0} \\
0\end{array}$ \\
\hline s!ıuәuеjeonk elu!djesəeo & $\begin{array}{l}8 \\
0\end{array}$ & : & : & $\overline{0}$ & 8 & 8 & $\bar{o}_{0}^{-}$ \\
\hline 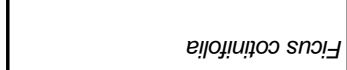 & 8 & 8 & 8 & 8 & 8 & $\begin{array}{l}\text { o. } \\
\text { o. }\end{array}$ & ণั \\
\hline eluop!n6 eluejənZ & 8 & 8. & 8 & 8 & ర్ & 8 & ণ్ \\
\hline unuejeonর un!ss!uкłeld & 8 & 8 & 8 & 8 & ণ్ & 8 & ช్ \\
\hline 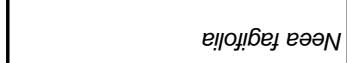 & 8 & 8 & 8 & 8 & Õ & 8 & స్ \\
\hline $\begin{array}{l}\frac{0}{0} \\
\mathbb{d} \\
0 \\
0 \\
\mathbb{0} \\
\overline{0} \\
\frac{\pi}{0} \\
\frac{0}{\overline{0}} \\
0\end{array}$ & $\begin{array}{l}\bar{\Phi} \\
\stackrel{\circlearrowright}{\widetilde{N}} \\
\widetilde{O}\end{array}$ & ב & 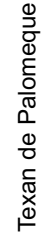 & 氧 & 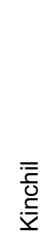 & 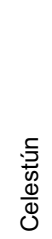 & $\begin{array}{l}\text { त्ञ } \\
\text { है }\end{array}$ \\
\hline
\end{tabular}




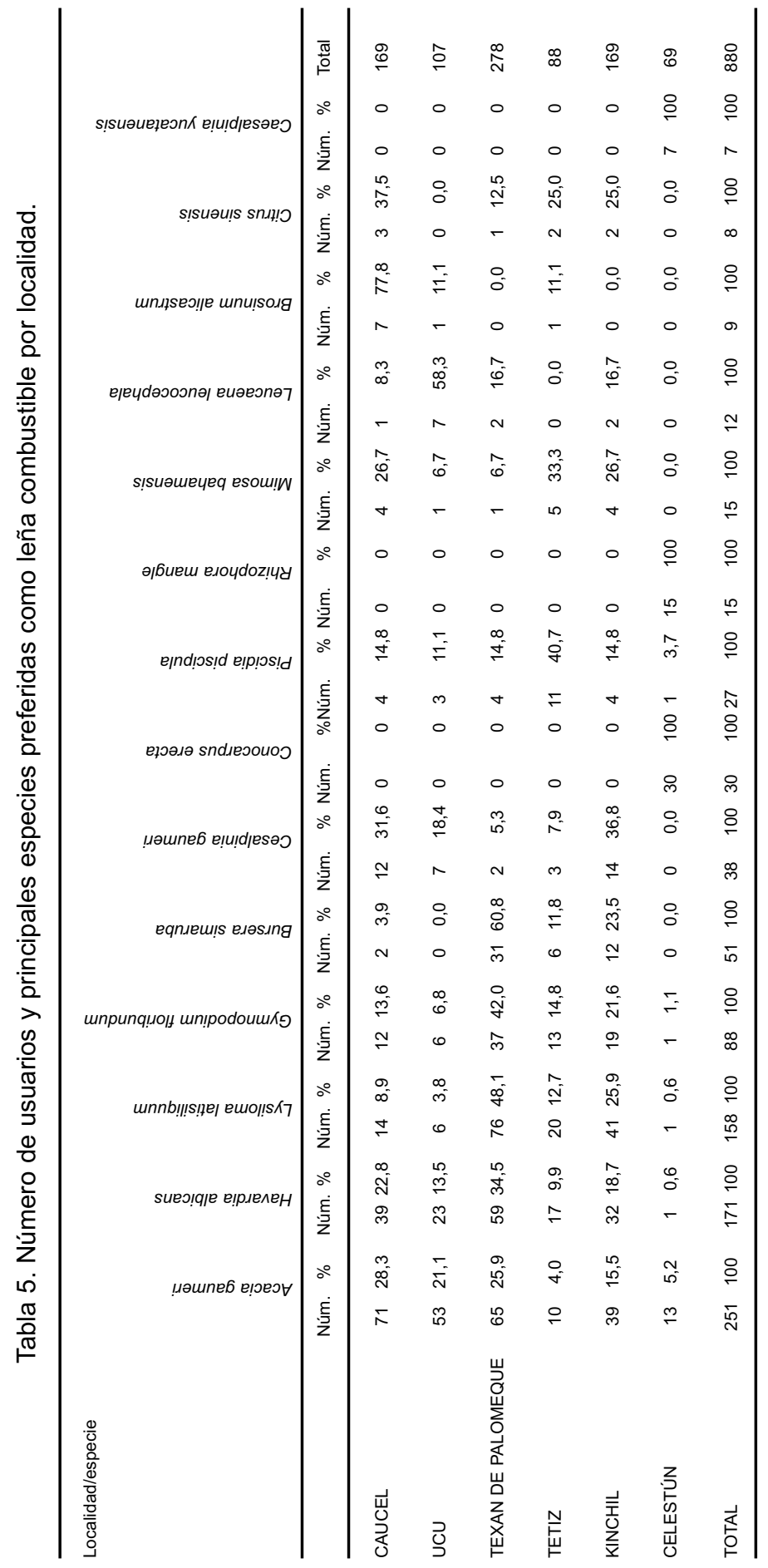


Por otra parte 217 informantes, desconocían los nombres locales de las especies utilizadas por ellos como leña o no fueron capaces de identificar los leños con los nombres comunes.

Las 13 especies principales, preferidas como leña y la frecuencia relativa en los hábitos de preferencia de los pobladores son: box katsim (Acacia gaumeri) 26,8\%, chukum (Havardia albicans) $18,3 \%$, tsalam (Lysiloma latisiliquum) $16,9 \%$, ts'i' ts'ilché (Gymnopodium floribundum) 9,4\%, chacáh (Bursera simaruba) 5,5\%, kitinché (Caesalpinia gaumeri) $4,0 \%$, botoncillo (Conocarpus erectus) $3,2 \%$, habín (Piscidia piscipula) 2,9\%, mangle ( Rhizophora mangle) 1,6\%, sak katsim (Mimosa bahamensis) 1,6\%, huaxim (Leucaena leucocephala) 1,3\%, ramón (Brosinum alicastrum) 0,96\% y naranja (Citrus sinensis) 0,85\% (Tabla 3).

Las especies con mayor frecuencia de uso relativa, coinciden también con las de mayor abundancia relativa encontrada en los muestreos de la vegetación (tablas 4.1 a 4.4 y 5 ) en los casos de Caesalpinia gaumeri, Lysiloma latisiliquum, Gymnopodium floribundum, Havardia albicans, Piscidia piscipula, Bursera simaruba $y$ Mimosa bahamensis. Lo anterior se debe a diversos factores entre los que destacan que la mayoría de éstas especies son leguminosas, excepto Gymnopodium floribundum y Bursera simaruba. Esta familia es un recurso disponible en cualquier tipo de vegetación y son especies con gran incidencia en las actividades humanas locales (Flores, 2001).

La información vertida por los informantes clave, sobre especies preferidas como leña coinciden, en su mayoría, con la abundancia relativa de las especies en los sitios de extracción, como se muestra en la tabla 4.1 a 4.4 . Las especies más abundantes kitinché (Caesalpinia gaumeri), tsalam (Lysiloma latisiliquum), ts' i' ts' ilché (Gymnopodium floribundum), chukum (Havardia albicans), mangle (Rhizophora mangle), habín (Piscidia piscipula), chacah (Bursera simaruba), sak katsim (Mimosa bahamensis), box katsim (Acacia gaumeri) y botoncillo (Conocarpus erectus).

\section{DISCUSIÓN}

El uso de la leña para combustible, sobre todo para cocinar y calentar agua para el baño, es una costumbre ancestral que, desde la perspectiva de análisis en los países industrializados se ha tomado como un indicador de los niveles de crecimiento económico de una región o país. Desde esa perspectiva se desconocen o no se valoran como es debido, las preferencias culinarias y la influencia de la leña en la diversidad de olores y sabores locales.

El consumo de leña es más elevado a escala mundial en los países del tercer mundo. En México su uso se da con mayor intensidad en el ámbito rural y urbano marginado. Esta situación es el resultado de diversas circunstancias desde las microeconómicas hasta las macroeconómicas como pueden ser a) la abundancia y/o disponibilidad del recurso, b) las preferencias y tradiciones, c) los procesos de acumulación capitalista que generaron países industrializados altamente consumidores de hidrocarburos y por otra parte países de economías deformadas con mayor consumo de combustibles derivados de biomasa.

En el escenario actual es importante someter a evaluación la práctica del consumo de leña para contestar las siguientes preguntas: ¿Cuál es el impacto de las emisiones de gases de efecto invernadero generadas por la combustión de leña, a escala micro-local, regional y global?, ¿Qué efectos socioeconómicos 
se presentarían si se restringiera o promoviera el uso de la leña a escala regional? Considerando los impactos sinérgicos de las múltiples actividades antropogénicas actuales, ¿puede considerarse a la leña un recurso renovable y potencialmente inagotable?.

En el universo de muestreo del presente trabajo ha resultado que el promedio del consumo de leña en la región fue de $2,06 \mathrm{~kg} / \mathrm{dia} / \mathrm{habitante}$, similar a lo reportado para la localidad de X-uilub, Yucatán, por Sánchez (1993) de $2,04 \mathrm{~kg} / \mathrm{día} / \mathrm{habitante}$. Pero con una variación entre la localidad de mayor y menor consumo de 1,63 kg/día/habitante; siendo la localidad de mayor consumo celestún y la de menor consumo Caucel. Esto representa que en los sitios de estudio, con una población usuaria de leña de 16686 habitantes, se consume aproximadamente 34,3 toneladas de leña al día, esto es 12519 toneladas por año. Esta cantidad de leña se consume en su totalidad en fogones abiertos o de tres piedras, lo que implica una gran cantidad de calor perdido por disipación, siendo un sistema poco eficiente. Los usuarios de leña se caracterizan por ser familias de bajos ingresos y la leña representa un energético disponible localmente. En la actualidad ha sido de una gran preocupación el tratar de optimizar el uso de la leña. Para conseguir esto se han rediseñado estufas tomadas a partir de algunas tradicionales, como es el caso de la patsari, que se ha extendido en el país. En Yucatán se han instalado prototipos y se trabaja con nuevos modelos (Quiroz et al, 2009).

Es importante destacar el conocimiento empírico que tienen los usuarios sobre las características físicas y químicas de la madera, que aún sin describir dichas características en el presente trabajo, hemos recogido testimonios de cómo las reconocen y las nombran. Por ejemplo para su uso en el fogón prefieren leña de especies que al arder no generan gran cantidad de humo, su combustión sea lenta y produzcan brasas o tizones. Estas propiedades les permiten clasificarlas localmente en especies de buena leña como el tsalam (Lysiloma latisiliquum), el habín (Piscidia piscipula), o el box katsim (Acacia gaumeri), de madera dura como el chukum (Havardia albicans) y en el otro extremo, las especies poco apreciadas 0 de madera suave como el chacáh (Bursera simaruba) o las ceibas.

Por otra parte también influye en el uso de las especies señaladas, las preferencias gastronómicas cotidianas y de las festividades locales, donde se utilizan aquellas especies que aportan olores y sabores agradables a los alimentos como es el caso del habín (Piscidia piscipula) y el kitimché (Caesalpinia gaumeri) para hornear enterrado el pib, que es el tamal de la festividad de muertos o mukbilpollo y el chukum (Havardia albicans) para la cocción del elote tierno o pibil naal.

Adicionalmente se puede señalar que las características biológicas de estas especies, como son el crecimiento rápido del pixoy (Guazuma ulmifolia), gran producción de semilla y capacidad de establecimiento de las plántulas en el tsalam (Lysiloma latisiliquum), el habín (Piscidia piscipula), el box kaatsim (Caesalpinia gaumeri), y el chukum (Havardia albicans) facilitan su abundancia y disponibilidad.

Cinco de las catorce especies mencionadas en la tabla 5 coinciden con lo reportado por Flores (2001), como especies preferidas para su aplicación como leña en las localidades de Sotuta, Chacmay, Dzan, Tizimín y Vallarta, estas son: box katsim (Acacia gaumeri), chukum (Havardia albicans), tsalam (Lysiloma latisiliquum), habín (Piscidia pisci- 
pula) y sac katsim (Mimosa bahamensis). El hecho que las especies que fueron reportadas en nuestro trabajo, no coincidan en su totalidad con las de Flores (2001), indican que sería necesario realizar inventario de uso de leña por región y poder valorar así el estado actual de las especies leñosas como recurso natural.

\section{CONCLUSIONES}

El consumo de leña para uso doméstico, bajo el esquema de aprovechamiento de ramas caídas y secas de los árboles, no altera la estructura y función esenciales del monte. De forma contraria, las comunidades vegetales resultan beneficiadas ya que al extraer la madera muerta se reduce el peligro de incendio, la presencia de plagas forestales y el aclareo favorece la renovación natural tal y como afirman Masera y Fuentes (2006), los procesos de perturbación de las comunidades vegetales en Yucatán son generados por otras actividades humanas.

Las especies más utilizadas representan las más apreciadas por lo habitantes a nivel microrregional, debido a que conocen sus características como son: la capacidad de generar calor, menor emisión de humo, los aportes al sabor y olor de los alimentos preparados, saben manejarlas, de acuerdo con Flores (2001) y con nuestros resultados y son abundantes en las áreas de colecta.

Bajo el esquema de manejo actual podemos esperar que la extracción de leña combustible se incremente entre $7 \mathrm{y}$ $10 \%$ anual, como una respuesta al crecimiento poblacional. Sin embargo, su disponibilidad podría reducirse a causa de otras presiones antropogénicas como son construcción de unidades habitacionales para trabajadores de Pemex, complejos industriales, turísticos, carreteras, unidades agropecuarias, entre otras. Es importante hacer estudios para conocer la capacidad de extracción de leña por unidad de superficie y así determinar la tolerancia de las comunidades vegetales a un ritmo de extracción creciente, así como la escasez potencial de leña a mediano y largo plazo. Ya que la percepción de los usuarios es que actualmente es más difícil obtener leña, respecto a años pasados.

De la misma forma es necesario identificar mecanismos para el establecimiento de plantaciones dendroenergéticas de uso público o comunitario, de tal forma que una medida de recuperación de la masa arbórea no se transforme en un proceso de control económico, político o burocrático, lo que finalmente encarecería el recurso al usuario final, que en esencia son de bajos ingresos. Las especies con las cuales iniciar procesos dendroenergéticos pueden ser las de mayor preferencia como son: box katsim (Acacia gaumeri), chukum (Havardia albicans), tsalam (Lysiloma latisiliquum), habín (Piscidia piscipula) y sac katsim (Mimosa bahamensis).

Si bien es cierto que la exposición al humo en el interior de los domicilios representa un factor ambiental de afecciones respiratorias agudas, es necesario evaluar el impacto de las emisiones sobre la salud humana de acuerdo al tipo de cocinas, debido a que en Yucatán éstas poseen grados de ventilación diferentes, por lo que las mujeres reciben emisiones de humo en cantidades diversas.

Además es necesario considerar en las agendas de desarrollo local y regional la aplicación de tecnologías no convencionales como son: la construcción y autoconstrucción de estufas de leña eficientes o de bajo consumo (Best et al., 2006; Quiroz et al., 2009), u otras tecno- 
logías no convencionales como la olla solar, calentador solar de agua, entre otras que permitan sostener o reducir el uso de la leña combustible, sin afectar los procesos tradicionales, minimizar el gasto económico en este tipo de energía y las emisiones a la atmósfera micro-local para reducir su efecto sobre la salud de las mujeres, niños y adultos mayores, que son la población, generalmente más expuesta a las emisiones derivadas de la combustión de biomasa.

\section{RECONOCIMIENTOS}

Se reconoce el apoyo otorgado por los Fondos Mixtos del Conacyt- Gobierno del estado de Yucatán al proyecto "Estudio sobre el uso y manejo de leña en los hogares de la región litoral oeste y metropolitana del estado de Yucatán, casos de estudio: Caucel, Ucú, Hunucmá, Tetiz, Kinchil y Celestún (número FOMIX-YUC_SA072/06)" del cual este artículo es uno de sus resultados. Así mismo se agradece a Paulino Simá Polanco su apoyo para la determinación botánica de los ejemplares de estudio y a Celene Espadas Manrique por la elaboración del mapa de los sitios de estudio.

\section{REFERENCIAS}

Arias Ch., T. 2002. Disponibilidad y uso de leña en tres micro-regiones del trópico mexicano. In: Silvia del Amo Rodríguez (Coord.) La leña: el energético rural en tres micro-regiones del sureste de México, una experiencia interactiva con la población local. Plaza y Valdez, S.A. de C.V., México D.F. p. 79-99.

Best B., G., I. E. Gómez M., J.E. Aguillón M., J. L. Arvizu F., R. Díaz J., R. B. Gamiño C y V. M. Berrueta S. 2006. Aplicaciones de las tecnologías bioenergéticas. In: La Bioenergía en México, un catalizador del desarrollo sustentable. Omar Masera Cerutti (Coordinador). Comisión Nacional Forestal. MundiPrensa, México, D.F. p. 33-65.

Campbell, J.A. 1998. Amphibians and reptiles of Northern Guatemala, the Yucatán and Belize. University of Oklahoma Press Norman, Oklahoma, USA. 380 p.

De Montalembert, M.R. y J. Clément , 1983, Disponibilidad de leña en los países en desarrollo. Estudio FAO: Montes 42. http://www.fao.org/docrep/X5329s/x53 29s00.htm\#Contents

Del Amo R., S. y P.L Yllescas H. 2002. Diagnóstico inicial del consumo de leña. Evaluación de las Alianzas Tripartitas. In: Silvia del Amo Rodríguez (Coord.) La leña: el energético rural en tres micro-regiones del sureste de México, una experiencia interactiva con la población local. Plaza y Valdez, S.A. de C.V., México D.F. p. 33-41.

Del Amo, R., S. 2002. Perfil y metodología del PROAFT, A.C. como organización no gubernamental. In: Silvia del Amo Rodríguez (Coord.) La leña: el energético rural en tres microregiones del sureste de México, una experiencia interactiva con la población local. Plaza y Valdez, S.A. de C.V., México D.F. p. 21-31.

Díaz J., R. 2000. Consumo de leña en el sector residencial de México, evolución histórica y emisiones de $\mathrm{CO}_{2}$. Tesis de maestro en ingeniería (energética). UNAM, División de estudios de Posgrado, Facultad de Ingeniería. México D.F. 113 p.

Duch G., J. 1991. Fisiografía del estado de Yucatán, su relación con la agricultura. 
Universidad Autónoma de Chapingo. Texcoco, México. 229 p.

Flores, J. S. 2001. Fabaceae. florística etnobotánica y ecología. UADY-FMVZ. Mérida, Yucatán, México. 320 p.

Flores, S. e I. Espejel. 1994. Tipos de vegetación de la Península de Yucatán. Etnoflora Yucatanense, fascículo 3. UADY-Sostenibilidad Maya. Mérida, Yucatán, México. 135 p.

García, E. 2004. Modificaciones al Sistema de clasificación climática de Köppen. Serie Libros No 6 . Instituto de Geografía, Universidad Nacional Autónoma de México. México. $90 \mathrm{p}$.

Ghilardi, A., G. Guerrero y O. Masera. 2007. Spatial analysis of residential fuelwood supply and demand patterns in Mexico using the WISDOM approach. Biomass and Bioenergy (31) 475-491.

Howell, S.N.G. y S. Webb. 1995. A guide to the birds of Mexico and Northern central America. Oxford University Press, Oxford. $850 \mathrm{p}$.

INEGI, 1990. Yucatán, Resultados definitivos. Tomo IV. Tabulados básicos. XI Censo general de población y vivienda. México. p. 1981-2072; 2073-2162.

INEGI, 2000. Anuario estadístico del Estado Yucatán. México. Disco compacto.

INEGI, 2000a. Sistema para la consulta de la Información Censal (SINCE). México. Disco compacto.

Lee, J. C. 2000. A field guide to the amphibians and reptiles of the maya world. Cornell University Press, New York. Estados Unidos. 395 p.

Ley Orgánica de los Municipios del Estado de Yucatán 1988. Diario Oficial del
Gobierno del Estado de Yucatán, 25 de octubre de 1988. Núm. 26, 210. Año LXXXVIII. Suplemento. 40 p.

Masera, O. y A. F. Fuentes G. 2006. Introducción. In: La Bioenergía en México, un catalizador del desarrollo sustentable. Omar Masera Cerutti (Coordinador). Comisión Nacional Forestal. Mundi-Prensa, México. p. 1-6.

Martínez, H. A. 1985. Producción de leña en la zona seca de Guatemala. In: Rodolfo Salazar (ed.) Actas de los simposios sobre técnicas de la producción de leña en fincas pequeñas y recuperación de sitios degradados por medio de la silvicultura intensiva, Centro Agronómico Tropical de Investigación y Enseñanza, Costa Rica. p. 77-88.

Olmsted, I. C., R. Durán, J. A. GonzálezIturbe, J. Granados y F. Tun. 1999. Vegetación. In: García de Fuentes, A., J. Córdoba, P. Chico, eds. Atlas de Procesos Territoriales de Yucatán. Facultad de Arquitectura, Universidad Autónoma de Yucatán-CONACYT. p. 183-194.

Orellana, R. 1992. Síndromes morfológicos y funcionales de las palmas de la Península de Yucatán. In: Bull. Inst. fr. Études andines. (21- 2): 651-667.

Orellana, R. y R. Durán. 1992. Las Palmas de la Península de Yucatán: un patrimonio que debemos conservar. Gaceta Universitaria (APAUADY) (14) 22-28.

Orellana, R., G. Islebe y C. Espadas. 2003. Presente, pasado y futuro de los climas de la Península de Yucatán. In: P. Colunga García Marín, A. Larqué Saavedra (eds). Naturaleza y Sociedad del Área maya. Pasado Presente y Futuro. Academia Mexi- 
cana de Ciencias y Centro de Investigación Científica de Yucatán. México. p. 37-52.

Parra V., M.R. 1989. El subdesarrollo agrícola en los altos de Chiapas. Universidad Autónoma de Chapingo, México. p.106-119.

Pelto P.J. y G.H. Pelto. 1978. Anthropological research. the structure of inquiry. Cambridge University Press, Nueva York. USA. 325 p.

Quiroz, J., C. Cantú G., R. Díaz J. y R. Orellana. 2009. Uso de la leña en Yucatán y tecnología para su aprovechamiento sustentable. Asociación Red Verde A. C. y Centro de Investigación Científica de Yucatán, A. C. Mérida. $74 \mathrm{p}$.

Reiche, C.E. 1985. La leña en el contexto socioeconómico de América Latina. In: Rodolfo Salazar (ed.) Actas de los simposios sobre técnicas de la produc- ción de leña en fincas pequeñas y recuperación de sitios degradados por medio de la silvicultura intensiva, Centro Agronómico Tropical de Investigación y Enseñanza, Turrialba, Costa Rica. p. 355-369.

Sánchez G., M. C. 1993. Uso y manejo de la leña en X-uilub, Yucatán. Etnoflora Yucatanense, UADY-Sostenibilidad Maya, Mérida. 117 p.

Sánchez A., R. L. y S. Rebollar-Domínguez. 1999. Deforestación en la Península de Yucatán, los retos que enfrentar. Madera y Bosques 5(2): 3 -17.

Vergara T., C. 2002. Talleres de sensibilización y diagnóstico sobre el uso de la leña en comunidades rurales. In: Silvia del Amo Rodríguez (Coord.) La leña: el energético rural en tres micro-regiones del sureste de México, una experiencia interactiva con la población local. Plaza y Valdez S.A. de C.V., México D.F. p. 55-77. 